\title{
An Analysis of Mortgage Arrears Using the British Household Panel Survey
}

\author{
Hollie Cairns and Gwilym Pryce, \\ Department of Urban Studies, \\ University of Glasgow \\ Contact: g.pryce@socsci.gla.ac.uk
}

\author{
Work in progress as at 20 ${ }^{\text {th }}$ April 2008: $\quad$ Please do not quote without permission
}

\section{ABSTRACT:}

In this paper we review the current literature on mortgage default in the UK and present preliminary results of a household-level pooled logit model of mortgage arrears based on twelve waves of the British Household Panel Survey (BHPS). Out goal is to use the model to bridge the gap in the UK mortgage default literature between models that emphasize an equity explanation of default, and those that assume an ability to pay explanation. Our model is also the first to examine the effectiveness of Mortgage Payment Protection Insurance in a large sample context (research on MPPI has tended to focus on take-up or has used relatively small sample analysis of effectiveness). We find that the odds of arrears increase with the probability of unemployment. While take-up of MPPI significantly reduces the odds of arrears, the effect is not as large as having savings (though both variables are measured crudely). Despite trying various measures, we found no evidence of an equity effect.

\section{Introduction}

What are the main factors that drive arrears and possessions? This article surveys the systematic studies of the drivers of mortgage repayment difficulties and summarises the evidence that is currently available. The paper is structured as follows: first we briefly consider the classification of factors that affect mortgage default risk. We then summarise the findings of the literature in relation to each driver of default with a view to evaluating which factors are the most important drivers of mortgage default and to identify the areas worthy of future research. We then present initial results from a model of arrears using the British Household Panel Survey.

\section{Classifying the Drivers of Arrears and Possessions}

Figure 1 sets out the main drivers of mortgage default. We have broken down the determinants of mortgage default into those factors that affect the chances of falling into arrears (trigger events, financial resources and financial commitments), and those that determine whether arrears lead to default (lender forbearance and court leniency). Arrears do not inevitably result in possessions, though one might expect a fairly stable relationship between the two, changing only if there are 
notable changes in the leniency of the courts/lender forbearance or in the financial incentives to default without arrears (i.e. defaulting not because of difficulty in repaying but with a view to maximising profit/minimising loss on an investment). Muellbauer and Cameron (1997, p.25), for example, find evidence that "there was a temporary softening of policy in the county courts beginning in 1991 but that court policy had returned to normal by 1995” (p. 25).

\section{Macro vs Micro Approaches}

Before discussing each driver, it is worth noting that another way to divide up the drivers of default is into macro and micro factors. The focus of the macro approach is not on what causes the incidence of arrears to vary between individuals, but what factors might cause the overall levels of default to vary over time. It is concerned with the aggregate level of default and how it is influenced by wider economic conditions. Potentially important drivers of arrears and possessions (such as bereavement, relationship breakdown, accident and sickness) may therefore legitimately be omitted from macro models if they are reasonably static over the time period considered. The advantage of the macro approach is that it can utilise published forecasts of future unemployment and interest rates to forecast future changes in headline arrears and possessions.

Consideration of macro models alone, however, will result in an incomplete picture of mortgage risk. First, the factors that drive arrears can vary considerably between regions and even within regions, and so macro estimates can mask large geographical variation. Second, the sensitivity of default rates to drivers may also vary geographically. OEF (2001, p.5), for example, found that "possessions in the wealthier, southern regions respond less sharply to changes in debt-servicing costs, debt-equity ratios and the rate of business de-registrations than do possessions in the poorer, northern regions”. This means that forecasts can be misleading if they are not computed at the appropriate spatial scale. Third, macro analysis does little to help the mortgage industry and policy makers distinguish between risks at the household level and hence target safety nets to those most in need. Aggregation of variables can mask important subtleties in the determination of default risk. For example, the ratio of aggregate mortgage debt relative to aggregate housing wealth (the debtequity ratio) does not exclude home owners who own their homes outright from the computation of housing wealth, yet these households are irrelevant to the determination of mortgage default. What we would really like to measure is the debt-service ratio for mortgage borrowers.

Data collected at the individual household level, such as the BHPS or SHE, has the advantage of allowing one to investigate why household A might be more likely to fall into arrears than household B. Factors such as the number of dependents and relationship breakdown might prove important micro drivers, even though they may not be particularly significant at the macro level. Changes in the average rate of divorce may have little impact on average arrears, but for the individual household, divorce may have a massive impact on the probability of falling into arrears. The micro approach is less amenable to producing forecasts of future change in the overall rate of arrears and possessions, but is potentially more useful in helping identify those most at risk, and in improving our understanding of the complex set of factors that cause mortgage default outlined in Figure 1. 
Figure 1 Drivers of Arrears and Possessions

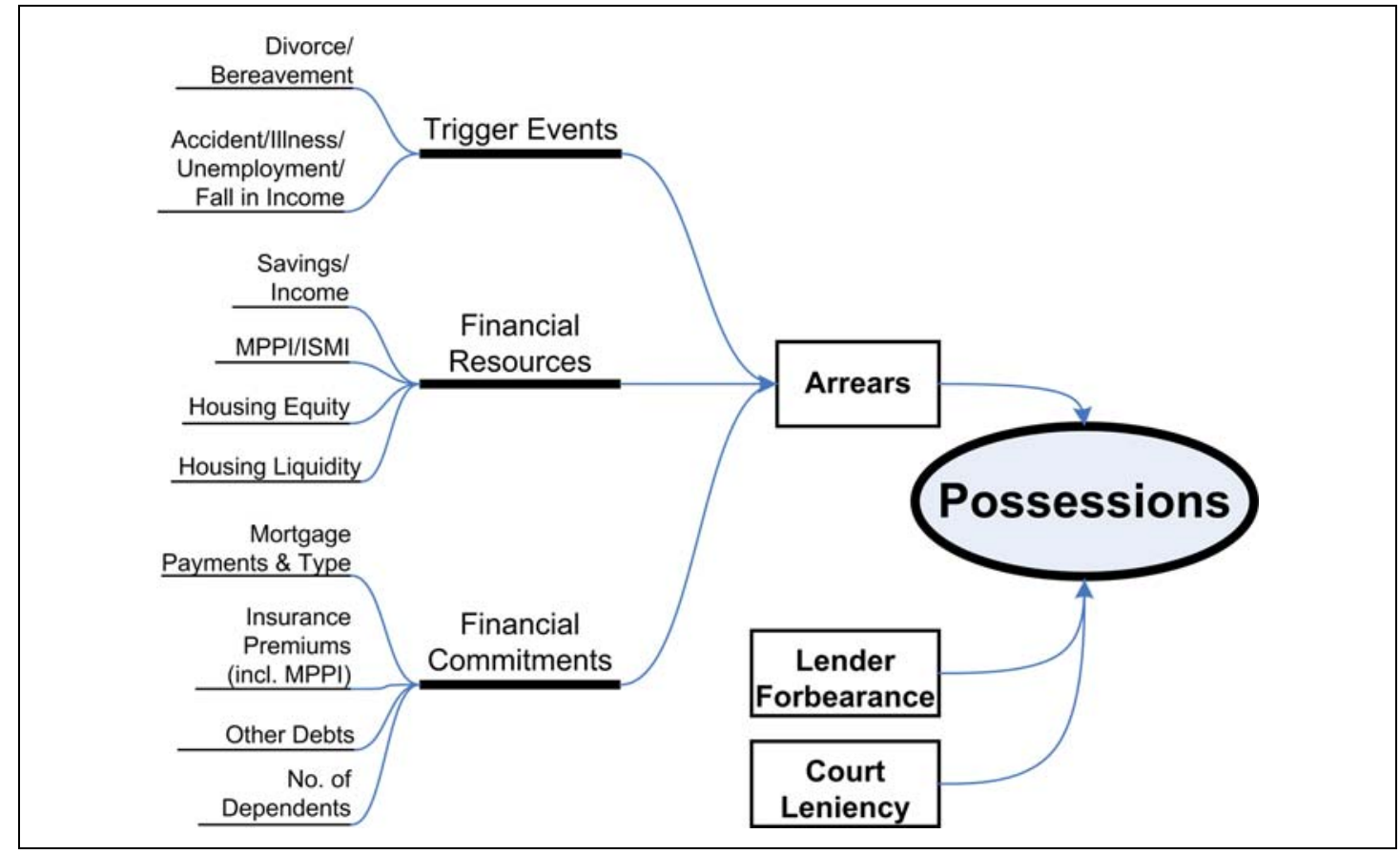

We shall turn now to each of the key categories of drivers of default and summarise the attempts in the literature to quantify the impact of each effect.

\section{Trigger Events}

\section{Unemployment}

While a range of factors associated with a household's financial circumstances (loan-to-value ratios, savings, household income, expenditure, Mortgage Payment Protection Insurance) can affect the household's ability to maintain mortgage payments, the importance of these factors does not usually become apparent until a household faces a “trigger event”. Unemployment, reduced income, illness and relationship breakdown, can scupper even the most carefully planned budget, leaving the household dependent on publicly provided safety nets and the hope of a reversal of fortunes. Of these trigger events, those most often cited as a cause of arrears are those related to employment. Ford et al's (2004, p.14) analysis of the Survey of English Housing (SEH) reveals that, for 1995 2003, “arrears resulted from labour market disruption (unemployment, failure of self-employment or reduced wages) in a majority of cases, constituting the most significant risk”. Labour market factors are important not only because of their direct role in driving arrears and possessions, but also because of their influence on other drivers of default risk, such as the risk of accident/illness (Cairns and Pryce 2004) and indeed the take-up of Mortgage Payment Protection Insurance (Pryce and Keoghan, 2001, 2002; Pryce 2002; for a brief description of these insurance policies see the discussion on MPPI below). 
Macro estimates by Oxford Economic Forecasting (2001, p.12) suggest that, holding everything else constant, a rise in the unemployment rate by $10 \%$ will eventually raise both arrears and possessions by $27 \%$. In comparison, a rise of $10 \%$ in the aggregate debt service ratio (aggregate interest payments relative to aggregate income), or the debt-equity ratio (aggregate mortgage debt relative to aggregate housing wealth), or income inequality or house price inflation will result in a rise in arrears and possessions of $0.5 \%, 33 \%, 47 \%$ and $0.5 \%$ respectively. This suggests that the aggregate rate of mortgage default is more sensitive to changes in unemployment than it is to changes in the debt service ratio or house prices, but less sensitive than it is to debt-equity or income inequality (though the level of inequality is unlikely to vary as much as the rate of unemployment in the short run). Note also that there is evidence that unemployment can affect the likelihood that arrears will lead to repossession. Muellbauer and Cameron (1997, p.32), for example, find that "an increase in the unemployment rate from 8 to $10 \%$ in the long run also implies an increase in the ratio of possessions to arrears of around 50\%”.

Micro models have been developed in the UK, but not all of these include the effect of unemployment (such as Lambrecht et al 1997). One study that does make a serious attempt at including the effect of unemployment in a micro model is the study by Boheim and Taylor (2000) which develops a comprehensive cross-tenure model of evictions and repossessions in Britain using data for the period 1991 to 1997 from the BHPS. They include both the regional unemployment rate and employment status of the head of household as possible determinants, and find the former to be marginally significant and the latter to be highly significant. Unfortunately, it is difficult to ascertain from the Boheim and Taylor model the relative importance of unemployment in determining arrears because the way the results are reported prohibits the reader from quantifying the impact of individual drivers. As such, we currently do not have a micro estimate of what the impact of a rise in unemployment of say ten per cent would be on the probability of mortgage default holding other factors constant. A potentially fruitful avenue for future research would be to incorporate the estimated probability of unemployment as a possible determinant of arrears, where this probability of unemployment is determined by both individual factors and local unemployment rates. This would allow policy simulations to be run that allow local unemployment rates to vary while holding individual factors constant (or visa versa).

\section{Change in Income}

Unemployment is not the only source of income change. Indeed, $10 \%$ of those surveyed in the 2003/2004 Survey of English Housing (SEH) cited lost income overtime, reduced hours or reduced pay as a reason for falling into arrears. However, simple headline percentages from the SEH do not tell us by what proportion income has to fall in order for arrears to increase by a given percent, nor does it tell us the effect of income changes in relation mortgage repayment costs or other fixed commitments. (Indeed, most lenders, when setting the terms of a mortgage contract, will consider not only total income, but also the relative value of income when compared to the amount borrowed and other factors). Using panel data, Boheim and Taylor (2000) consider the impact of current total 
income (but find this to be insignificant) and incorporate a range of financial indicators, including whether a household experienced a positive or negative financial surprise over the preceding year and whether a household received Income Support in the previous year. Boheim and Taylor find that "negative financial surprises are an important route into housing payment difficulties, which in turn are a significant predictor of subsequent eviction” (p. 312). They also find that "positive surprises are associated with a reduced likelihood of reporting housing payment problems, and negative surprises have the opposite effect...sudden unexpected deterioration in a household's financial situation is an important trigger for repayment problems” (p. 307). Again, due to the way Boheim and Taylor present their results, it is not possible to quantify these effects. While the results are interesting, because of the long list of inter-related variables included, it is difficult to derive straightforward conclusions from their results (particularly since receipt of Income Support is not independent of the employment status of the head of household, and is complicated by potential entitlement to ISMI). A useful direction for micro research would be to explore the sensitivity of the incidence of arrears to changes in the loan-to-income ratio or similar such measure, where the measure of income is "equivalised" to account for the number of dependents. While simple relative income measures have been attempted at the macro level the micro literature remains relatively undeveloped in this regard. Whitley et al (2004, p.20), for example, find that a one percentage point increase in the debt service ratio (i.e. total debt interest payments relative to disposable income) raises the proportion of mortgage loans in arrears by between 0.3 and 2.6 percentage points. OEF (2001) find arrears and possessions to be rather less sensitive to interest and income: a 10\% rise in the debt service ratio results in arrears and possessions of just $0.5 \%$.

\section{Divorce/ Bereavement}

A significant proportion (21\%) of those that experienced mortgage arrears list the death of a partner or relationship breakdown as a contributory factor (SEH 2002/2003). Quantifying the importance of this effect relative to other effects is not straightforward, however. Both Burrows (1998) and Boheim and Taylor (2000) find that household heads described themselves as "divorced or separated” were more likely to be in arrears (Burrows, 1998 p.13, estimates that heads of households who are divorced or separated are almost 1.8 times more likely to be in arrears). However, while Boheim and Taylor (2000) find that the variable had a significant effect on arrears, they find that it does not have a significant effect on eviction (they also find that being widowed actually reduces the risk of eviction but raises the risk of payment problems). Burrows concludes that, "although there clearly is an association between relationship breakdown and the odds of being in mortgage arrears, the size and strength of the association does not correspond to the importance consistently attached to it by mortgage lenders” (Burrows, 1998, p. 13).

These results have to be treated with caution because neither study considers how recently the relationship breakdown occurred and this is obviously crucial to the impact on the households ability to meet current mortgage payments. Although it is not possible to derive a dynamic measure of relationship breakdown from snapshot surveys such as the SEH, it would be possible do this with a longitudinal survey such as the BHPS. It is a potentially important factor since it is currently not one of the risks that the borrower can insure against by purchasing MPPI. 


\section{Illness}

In contrast to the absence of cover for relationship breakdown, ill health due to accident or sickness is one of the standard areas of protection included in MPPI packages (though subject to exclusions, see Kempson et al 1999 and Kemp and Pryce 2001) and one of the main causes of arrears. Since 1998, lost earnings through sickness or injury have accounted for between 18\% and 26\% mortgage arrears in the SEH (Ford et al 2004). Burrows (1998) attempts to account for the effect in the current status of head of household variable. He finds that those who are unable to work are around 4.5 times more likely to be in arrears. Macro models have not attempted to incorporate the effect of illness, assuming that its role in determining the overall level of arrears remains constant over time. However, as with unemployment and relationship breakdown, the timing of the event should also be incorporated, since a respondent may be healthy at the time of interview, but may have accrued substantial arrears following a recent bout of ill health.

Note that these 'trigger' events are neither mutually exclusive nor entirely independent. Unemployment, sickness and relationship breakdown can each occur simultaneously and each has the potential to precipitate the other. Though models of arrears and default (such as Burrows and Boheim and Taylor) allow for multiple causation, they do not explore the effect of one cause on another (that is, they generally assume the causes to be independent, but not mutually exclusive). While Boheim and Taylor include all the relevant 'trigger events' in their model, unfortunately it is not possible to compare the size of each of the 'trigger event' effects because of the way the model is presented.

\section{Financial Resources}

\section{Savings}

How well households cope with the upheavals of the trigger events discussed above depends critically on the financial resources that the household can draw upon. Savings play a crucial role in this regard offering a vital buffer in times of crisis. Unfortunately, those most at risk of losing their job and other negative events are also the least likely to have accumulated savings (Pryce and Keoghan 2002). None of the micro models of mortgage risk analysis in the UK (Burrows 1998, Lambrecht 1997, Boheim and Taylor 2000) consider this factor - largely because of the difficulty of obtaining a reliable measure of savings from survey data. It is an effect that could in principle be captured at the macro level, but none of the macro models we surveyed included this variable.

\section{$\underline{M P P I}$}

In 1995 major reforms were introduced to the state safety net for mortgage borrowers (see Ford et al 2004). Most notably, the waiting period before borrowers could receive their first payment of Income Support for Mortgage Interest (ISMI), rose to 39 weeks. Central to the success of these reforms was the premise of widespread take-up of private insurance in the form of Mortgage 
Payment Protection Insurance (MPPI). In return for a monthly premium based on the size of monthly mortgage costs, these policies typically cover the borrower's mortgage payments for up to 12 months in the event of unemployment or illness. While progress has been made in improving the quality and consistency of these products, concerns remain about the relatively low levels of take-up. In 1999 lenders and government set a target of 55\% take-up of MPPI by 2004, but the most reliable estimates suggest that take-up remains at less that half that figure (Ford et al 2004, p.15).

Given the policy importance of MPPI, perhaps the most surprising omission from both micro and macro models of mortgage risk, therefore, is the role of MPPI in ameliorating that risk. While there has been no shortage of qualitative and bivariate research on the pros and cons of MPPI, and a fair amount of quantitative analysis examining the take-up of MPPI (Pryce and Keoghan 2001; Pryce 2002; Ford et al 2004), there is an absence of quantitative research on the overall effectiveness of MPPI in preventing arrears. This includes the OEF study, which looks at the implications of their model for how MPPI should be targeted, but does not examine the effect of MPPI on the probability of arrears. An important future avenue of research, particularly at the micro level, would be to consider the relative effectiveness of MPPI and savings in reducing the risk of arrears. Holding everything else constant, by what proportion does the purchase of MPPI reduce the odds of arrears? Failure to answer this most basic of questions is perhaps the greatest shortcoming of the existing UK mortgage default literature.

Because savings and MPPI are, to some extent, competing strategies to safeguard against repayment difficulties, one would ideally like to measure their relative effects. An important future avenue of research, therefore, would be to include both MPPI and savings in a household level model of arrears in a way that will allow us to understand the relative effectiveness of these two factors in averting mortgage risk. The state safety net, Income Support for Mortgage Interest, is also a potentially important factor though it is unlikely that its effect could adequately be captured in a quantitative micro model because of the complex way eligibility rules interact with other drivers of default risk (such as income, unemployment and savings).

\section{Financial Commitments}

\section{Interest Rates and Mortgage Characteristics}

The most obvious factor to affect the 'outgoings' side of the household balance sheet is the rate of interest. This has a far greater short-run impact in the UK than many other developed countries because of the prevalence of variable rate and short-term fixed rate mortgages (rather long-term fixed rate mortgages common in the US - see Miles, 2004). As a result, mortgage interest rates, typically captured in the aggregate debt service ratio (total debt interest payments relative to disposable income), have proved to be a key variable in UK macro models of default. OEF (2001, p.12 and 13), for example, find that a 10\% rise in the aggregate debt service ratio would result in a $3 \%$ rise in arrears and a $9 \%$ increase in mortgage possessions. The long-run effect (5 years or more) is much smaller, however. OEF find that a $10 \%$ increase in the debt service ratio raises arrears by 
just $0.5 \%$. This is perhaps surprising since it suggests that default risk is relatively insensitive to interest rate changes. Note, though, that the effect is much larger in regions where debt servicing levels are already very high (such as London - see OEF, 2001, p.5). This is because a rise in interest rates in such regions will cause a much larger increase in total debt servicing costs relative to total income.

It should be noted, however, that the impact of changes to the base rate varies enormously between households, depending on the duration, type and size of mortgage. It is in fact a very particular subset of borrowers that will be likely to experience the predicted increase in possessions following an interest rate rise. For example, a household with a mature repayment mortgage is likely to be relatively immune to base rate changes, because in the final stages of such a mortgage, the lion's share of monthly mortgage payments are devoted to amortization capital. Conversely, those with endowment mortgages or newly acquired repayment mortgages will find that their mortgage payments are much more sensitive to interest rate changes. It is surprising, then, that Burrows (1998) finds that households with interest only mortgages are less likely to be in arrears (he explains this result is possibly the consequence of lenders moving problem borrowers onto repayment mortgages, though there is currently no empirical verification of this).

What about mortgage duration and the length of stay? The UK evidence is again somewhat ambiguous. While Lambrecht et al (1997) finds that the risk of default typically declines steeply with the maturity of the mortgage (risk of default usually peaks within the first year, holding other factors constant) other studies have not found a significant effect (Burrows and Boheim and Taylor find that length of stay does not significantly reduce arrears - neither consider the duration of the mortgage, but length of stay might be considered a proxy). The discrepancy in findings may be due to complications caused by the particular time periods considered, and the idiosyncrasies of the samples used.

\section{Dependents}

Another potential driver of household expenditure is the number of dependents. Boheim and Taylor (2000) incorporate the number and ages of children with mixed results. They find that 'the probability of eviction falls with the number of children' (p. 312) but the effect is reversed when they look at the probability of arrears; both eviction and arrears risks increase if the household has children aged under six. Burrows (1998, p. 12) finds that compared to couples with no dependent children, the odds of arrears are 56\% higher among couples with children, and 92\% higher for single men. That the results are contradictory and difficult to interpret is probably due to the fact that it is the number of dependents relative to income that is the crucial driver. As noted above, the most appropriate way of addressing this effect is to use "equivalised" income, but this approach has yet to be adopted in UK studies of mortgage risk. As such, there is currently no study that is able to demonstrate that there exists a household structure effect over and above the impact on disposable income. 


\section{Other Debts}

The servicing of other debts can place a significant burden on household finances. Again, none of the micro studies we considered included this factor in their models, most likely because of limited information on unsecured debt. Macro models, however, can make use of aggregate data on unsecured debt. OEF (2001), for example, include non-mortgage debt in their measure of aggregate debt servicing (total debt interest payments relative to disposable income). They find that a $10 \%$ increase in the debt service ratio raises arrears by just $0.5 \%$ in the long run.

\section{Other Factors:}

Two other factors have been considered as possible drivers of arrears and possessions: age of borrower and whether or not the house was purchased from a Local Authority (Right to Buy), both of which may have a direct 'behavioural' effect on the ability to pay, but may also have an indirect via one or more of the causes already considered. Burrows (1998) finds that younger borrowers are significantly more likely to fall into arrears (compared with those in the 45-54 age bracket, the odds of arrears was more than three times as high for borrowers aged 18-24, 31\% higher for those aged 25-34, and 22\% higher for those aged 35-44). However, because Burrows does not control for equivalised disposable income or outstanding mortgage debt, it is not clear whether this effect arises because older borrowers have fewer financial commitments, or because they have smaller mortgages, or whether it is because they are more skilled at managing their finances. Boheim and Taylor (2000, p.307) find that age has a significant effect on the incidence of arrears ("risk increases until the age of 38 and declines thereafter") even when mortgage and income factors are controlled for although the estimation method they adopt does not actually hold other factors constant (in a probit regression, because of the non-linear structure of the estimation routine, all variables interact with each other; one of the advantages of the logit approach adopted by Burrows is that log odds ratios can be used which do indeed allow the researcher to hold other factors constant).

Regarding Right to Buy, Burrows finds that borrowers who purchased their home from Local Authorities, New Town Corporations or Housing Associations were no more likely to fall into arrears than those who purchased dwellings from private owners once other factors were taken into account.

\section{Equity and Liquidity Drivers of Arrears and Possessions}

\section{Housing Equity}

Micro research in the UK has overwhelmingly focussed on "ability to pay" drivers of possessions, but there is another source of risk which literatures in other countries have considered. Housing equity, the difference between the market value of a property and the outstanding mortgage debt, has the potential to affect a borrower's incentive to continue with mortgage payments. It has been proposed by a number of authors (e.g. Jackson and Kaserman 1980, p.678) that borrowers base their 
default decisions on a rational comparison of the financial costs and returns involved in continuing mortgage payments. If a borrower's LTV exceeds one (negative equity), he/she has an incentive to default. A large US literature has emerged founded on this proposition (Kau et al 1992, 1995, 1999, Foster and Van Order 1984, 1985). The typical conclusion from such models is that the current loan-to-value ratio (LTV) will be a key, if not pre-eminent, driver of default risk (Case and Shiller, 1996), though the full force of this effect is only likely to be revealed when combined with a trigger event (such as loss of employment, ill health or the offer of a job in another part of the country).

The only $\underline{\text { micro }}$ study to date to consider the equity driver of default using UK household level data is Lambrecht et al (1997). They found no evidence that housing equity affects the probability of default. In fact, they found that households with low LTVs actually defaulted more quickly. This contrasts with the UK $\underline{\text { macro }}$ literature which typically estimates a very large equity effect. OEF (2001), for example, estimate that a ten per cent rise in the housing debt-equity ratio would result in a 13\% (19\%) increase in arrears (possessions) in the first 18 months and a 33\% (60\%) increase after five years. The size of macro estimates is puzzling and may reflect the impact of other factors correlated with housing equity (such as housing liquidity - see below).

The Lambrecht et al study, however, has a number of serious data problems: their sample is not random (it is drawn from an insurance claims database) and their measure of equity is the initial loan to value ratio. The only other variables considered are initial salary, marital status and the initial interest rate of the mortgage. Use of the initial loan to value ratio to measure the equity effect has three significant drawbacks. First, recent US research (Harrison et al 2004) suggests that bad risks may actually choose lower initial LTVs (a "self selection" effect), which complicates the relationship between initial debt gearing and default risk. Second, lenders may restrict the maximum LTV available to a borrower. Whitley et al (2004, p.23), for example, argue that the apparently negative effect of LTV on arrears "is consistent with it being used as a screening mechanism by banks to avoid risky customers”. Third, following periods of rapid house price growth (as recently experienced in the UK), for many borrowers initial loan to value ratios may bear little relation to current housing equity.

Also, housing equity may affect borrower's ability to repay, not just their incentive to repay. For example, reductions in housing equity may affect a household's ability to cope with financial shocks by "reduc[ing] their opportunity to remortgage to consolidate other debts or to lower their monthly payments" (CML, 2005, p.14). There are also negative macro feedback effects, both through reduced potential for equity conversion, and also through the impact on consumer confidence, both of which will have a negative affect on aggregate consumer demand, unemployment and, by extension, borrower's ability to meet monthly mortgage repayments. There are also potentially negative effects on labour mobility if housing equity is negative or insufficiently large to cover the costs of moving to new job opportunities which could potentially undermine labour market efficiency and exacerbate unemployment rates (Maclennan et al 1997). 


\section{Liquidity of Housing Assets}

Another potentially important way in which the state of the housing market can affect arrears and possessions is the impact of housing market buoyancy on average sale times, which in turn has a profound effect on asset liquidity - the ability of home owners to translate their housing assets into cash. In principle, a borrower in arrears could "sell their way" out of repayment difficulties. That is, they could avoid repossession by selling their home to repay the outstanding mortgage debt and move to a more affordable property or into rented accommodation, and hence avoid impairing their credit rating. If the market is flat, however, this is much more difficult to achieve within a time frame that would avoid further arrears and possession. And if the market has fallen to the extent that the borrower faces negative equity, selling the house to avoid possession may be no alternative at all. To our knowledge, no estimates currently exist on the effect of liquidity in avoiding repossession even though it is a potentially important component of what macro models are currently interpreting as an 'equity' effect. Given the large variation in housing liquidity between housing submarkets (see Pryce and Gibb 2004) this would ideally involve analysis at the sub-regional or household level of liquidity adjusted house prices.

\section{Which Drivers of Default are most important?}

Considering the UK evidence as a whole, we would conclude that labour market factors dominate the determination of mortgage default. This is not only because of the direct role that redundancy and reduced overtime play in causing arrears, but also because of the indirect effect of these factors in influencing other causes of default, such as the risk of accident or illness, the ability to save, the accumulation of other debts, and indeed the take-up of MPPI. Labour market factors also vary perhaps more than any of the other main drivers of default. This is because labour market conditions vary not only over time, but also across regions and also between individual households.

Interest rate changes do not seem to have a large long-term effect on aggregate default rates, though the impact varies by region (depending on the levels of existing aggregate debt servicing costs), and the effect is much larger in the short-run. Evidence on the impact of type and duration of mortgage on risk of default is currently ambiguous, as is the evidence on the impact of the number of children. Age of borrower has a very large effect - older borrowers are much less likely to default. Illness also appears to be a very important driver, though it is difficult to disentangle the risk of illness from labour market factors. Evidence on Right to Buy purchasers suggests that they are no more likely to default than any other group (once other factors are controlled for). The impact of relationship breakdown also appears to be relatively small (though there is some ambiguity in current estimates).

Regarding the effect of housing equity (whether borrowers tend to default when the value of their house falls below the value of their mortgage), there is an apparent contradiction between micro and macro estimates. Macro estimates suggest a huge equity effect (in some cases dominating even the impact of unemployment rates), whereas current UK micro studies find no equity effect at all. 
None of the studies we considered estimated the impact of savings, MPPI or liquidity on reducing arrears, so it is not possible to say at present how important these factors are.

\section{Priorities for Research}

Particular attention needs to be given to resolving the apparent contradictions in the evidence on the impact of housing equity. This is a high priority given the apparently huge effect estimated by the macro studies, and the less than optimistic house price forecasts from some market analysts. Also important is the need to quantify the impact of MPPI on reducing the risk of arrears. The role of liquidity is potentially important, but not well understood at present and is therefore also a worthy candidate for future research.

More generally, though, there is a need to standardise the presentation of estimates of the relative impact of different drivers of arrears, particularly in micro studies. Whereas macro studies have presented relatively easy to understand quantitative estimates of the impact of particular drivers (the $\%$ impact on arrears/possessions of a $10 \%$ rise in a driver, for example), most micro studies fail to do this. Consequently, it is difficult to ascertain the relative importance of factors considered in these studies. There are also a number of methodological problems associated with existing micro models which we have not covered in this paper but which are important and need to be addressed in future research. An added benefit of improving micro based research is that it could potentially lead to more reliable predictions of the default risk of individual households. This would help the mortgage industry and policy makers develop more appropriate safety nets and more easily target those most at risk.

\section{Preliminary Logit Analysis:}

The aim of this initial analysis is to use BHPS as repeated cross section to test the strength of the equity effect using a variety of measures of current LTV, with and without initial LTV. We attempt to create a parsimonious model by including Cairns’ 2004 estimated labour market risks variable, predicted from a probit regression of labour market status on $\mathrm{HoH}$ characteristics, year dummies and LA district dummies. We also aim to estimate the relative impact of of MPPI take-up and savings.

\section{Results:}

We experimented with a variety of measures of housing equity (perceived current LTV, predicted current LTV (simple), predicted current LTV (Hedonic), perceived capital gain, predicted capital gain (simple), predicted capital gain (Hedonic), predicted percentage capital gain (Hedonic) and predicted change in LTV (Hedonic)); along with a simple predicted probability of unemployment measure, age, MPPI take-up, and savings. 


\section{Logit Model of Arrears}

Table A: Testing the Equity Theory of Default

\begin{tabular}{|c|c|c|c|c|}
\hline & $\begin{array}{l}1 \\
\text { Perceived } \\
\text { Current LTV }\end{array}$ & $\begin{array}{l}2 \\
\text { Predicted } \\
\text { Current LTV } \\
\text { (simple) }\end{array}$ & $\begin{array}{l}3 \\
\text { Predicted } \\
\text { Current LTV } \\
\text { (Hedonic) }\end{array}$ & $\begin{array}{l}4 \\
\text { Perceived } \\
\text { Capital Gain }\end{array}$ \\
\hline Initial LTV & $\begin{array}{l}1.000 \\
(0.017) \\
1.000 \\
(-0.178)\end{array}$ & $\begin{array}{l}1.009 \\
(1.876) \\
0.991 \\
(-1.319)\end{array}$ & $\begin{array}{l}1.000 \\
(0.017) \\
1.000 \\
(-0.048)\end{array}$ & $\begin{array}{l}1.000 \\
(0.024) \\
1.000 \\
(-0.295)\end{array}$ \\
\hline & $\begin{array}{l}5 \\
\text { Predicted } \\
\text { Capital Gain } \\
\text { (simple) }\end{array}$ & $\begin{array}{l}6 \\
\text { Predicted } \\
\text { Capital Gain } \\
\text { (Hedonic) }\end{array}$ & $\begin{array}{l}7 \\
\text { Predicted \% } \\
\text { Capital Gain } \\
\text { (Hedonic) }\end{array}$ & $\begin{array}{l}8 \\
\text { Predicted \% } \\
\text { Change in LTV } \\
\text { (Hedonic) }\end{array}$ \\
\hline $\begin{array}{l}\text { Initial LTV } \\
\text { Equity Variable } \\
\text { + Control Variables }\end{array}$ & $\begin{array}{l}1.000 \\
(0.051) \\
1.000 \\
(-0.054)\end{array}$ & $\begin{array}{l}1.000 \\
(-0.047) \\
1.000 \\
(1.585)\end{array}$ & $\begin{array}{l}1.000 \\
(0.051) \\
1.000 \\
(-0.054)\end{array}$ & $\begin{array}{l}1.000 \\
(0.012) \\
1.000 \\
(-0.341)\end{array}$ \\
\hline
\end{tabular}

The equity variable in regression 1 is the perceived current LTV (or LTVc), where the value (or Vc) is the owners perception of the current value of the house. The equity variable in regression 2 represents the value of the house calculated using the original purchase price adjusted by regional house price inflation indices. Equity in regression 3 was calculated using a hedonic estimate of the current value. The equity variable in regression 4 is the owner's perception of capital gain, calculated as perceived current value minus the original purchase price of the property. In regression 5 , the equity variable is the predicted capital gain, computed as original purchase price adjusted by regional house price inflation indices minus original purchase price of the property. The equity measure in regression 6 is predicted capital gain, which is calculated using the hedonic estimate of the current value minus the original purchase price. Equity in regression 7 is defined as the owner's perception of capital gain, where capital gain is measured as a percentage change in the value of the house (hedonic). And finally, the equity variable in regression 8 is the percentage change in the LTV ratio (hedonic). As can be seen from the results of the various equity variables, none of the equity variables are statistically significant effect on the odds of arrears. These results did not change when we ran the eight regressions again without the initial loan to value ratio variable (see Table B). Our results appear to reinforce the apparent contradiction between micro and macro studies in terms of the impact of housing equity on the probability of default.

Table B: Testing the Equity Theory of Default

\begin{tabular}{|l|l|l|l|l|}
\hline & $\begin{array}{l}\text { Perceived } \\
\text { Current LTV }\end{array}$ & $\begin{array}{l}2 \\
\text { Predicted } \\
\text { Current LTV } \\
\text { (simple) }\end{array}$ & $\begin{array}{l}3 \\
\text { Predicted } \\
\text { Current LTV } \\
\text { (Hedonic) }\end{array}$ & $\begin{array}{l}\text { Perceived } \\
\text { Capital Gain }\end{array}$ \\
\hline
\end{tabular}




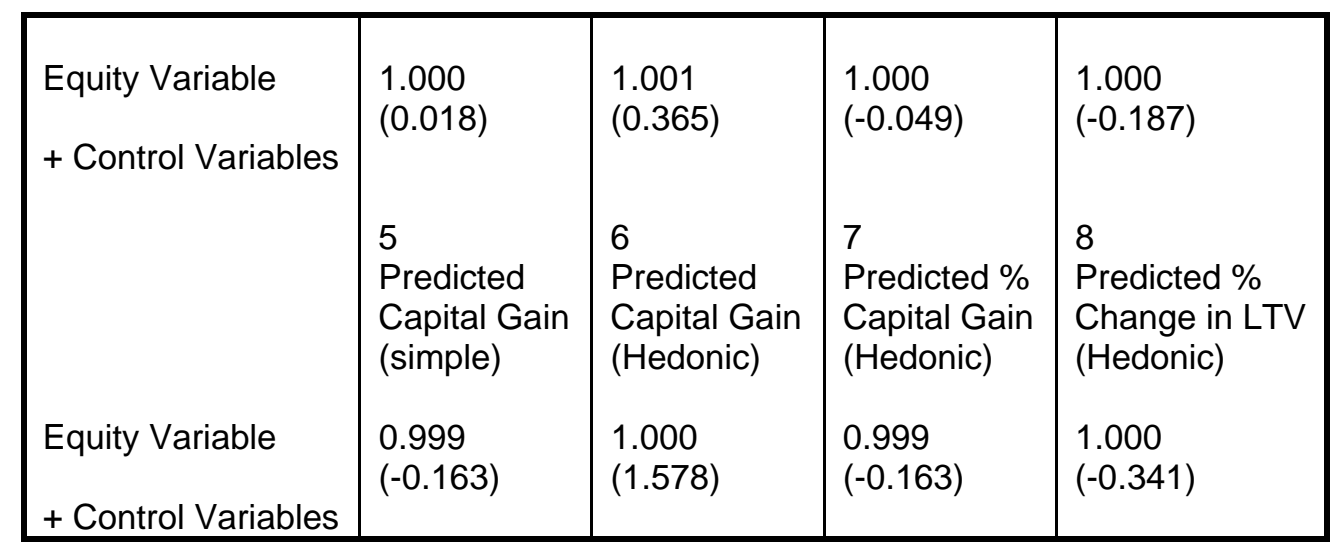

Is there evidence of an Ability to Pay Effect? And does MPPI significantly reduce the risk of mortgage arrears?

Table C: Evidence of an Ability to Pay Effect

\begin{tabular}{|l|l|}
\hline Pr(Unemp) & 1.096 \\
& $(10.199)$ \\
Savings & 0.164 \\
Sep/Divorced & $(-12.152)$ \\
& 2.937 \\
MPPI & $(9.78)$ \\
& 0.698 \\
Age & $(-3.310)$ \\
& 0.978 \\
+year & $(-4.939)$ \\
dummies & \\
& \\
Pseudo $R^{2}$ & 0.147 \\
$\mathrm{~N}$ & 26,667 \\
\hline
\end{tabular}

The probability of unemployment increases the odds of experiencing mortgage arrears and is highly significant. MPPI also has a significant effect in reducing the odds of arrears, but the reduction is not as great as that of savings (though both variables are measured relatively crudely). 
Has there been a change in the link between arrears and unemployment and MPPI since 1995?

Table D: ISMI Change

\begin{tabular}{|l|l|l|l|l|l|l|}
\hline & 1 & 2 & 3 & 4 & 5 & 6 \\
Initial LTV & 1.000 & & & 1.000 & & \\
& $(0.025)$ & & $(0.016)$ & & & \\
Pr (Unemp) & 1.128 & 1.098 & 1.143 & 1.096 & 1.098 & 1.096 \\
& $(5.261)$ & $(8.591)$ & $(7.015)$ & $(10.199)$ & $(8.559)$ & $(10.229)$ \\
UA95 & $\mathbf{1 . 0 4 1}$ & $\mathbf{0 . 9 9 4}$ & & & $\mathbf{0 . 9 9 4}$ & \\
& $\mathbf{( 1 . 0 0 1 )}$ & $\mathbf{( - 0 . 3 1 7 )}$ & & & $\mathbf{( - 0 . 3 0 2 )}$ & \\
Savings & 0.157 & 0.164 & 0.159 & 0.164 & 0.164 & 0.164 \\
& $(-6.419)$ & $(-12.145)$ & $(-6.382)$ & $(-12.152)$ & $(-12.147)$ & $(-12.149)$ \\
MPPI & 3.921 & 2.941 & 3.893 & 2.937 & 2.937 & 2.940 \\
& $(6.536)$ & $(9.795)$ & $(6.500)$ & $(9.78)$ & $(9.078)$ & $(9.795)$ \\
MPPIA95 & 0.720 & 0.770 & 0.775 & 0.698 & 0.699 & 0.769 \\
& $(-1.316)$ & $(-1.784)$ & $(-1.299)$ & $(-3.310)$ & $(-3.296)$ & $(-1.800)$ \\
& $\mathbf{1 . 1 5 9}$ & $\mathbf{0 . 8 0 9}$ & & & & $\mathbf{0 . 8 1 0}$ \\
& $(\mathbf{0 . 3 6 2 )}$ & $\mathbf{( - 0 . 9 7 0 )}$ & & & & $(-0.965)$ \\
\hline
\end{tabular}

To investigate whether the impact of unemployment risk and MPPI on arrears changed following the reforms to ISMI in 1995, we re-ran the regressions with two interactive variables:

$$
\begin{aligned}
& \text { UA95 = pr(unemp) } * \text { dummy for after } 1995 \\
& \text { MPPIA95 = MPPI * dummy for after } 1995
\end{aligned}
$$

If the estimated proportionate change in odds associated with the interactive terms is significantly different from 1, then there has been a change in the relationship since 1995. From the table above, it can be seen that values associated with both the UA95 and MPPI95 are close to one which suggests that there has not been a change in the relationship between MPPI, unemployment and arrears post 1995 . Note, however, that the labour market conditions remained relatively benign in our current sample - we have yet to see the impact of the new ISMI rules during a recession.

\section{Conclusion:}

The current literature suggests that mortgage default is driven by a complex set of factors that affect a household's incentive and ability to repay. Evidence is surprisingly ambiguous regarding the effects of many of the factors often assumed to be important drivers of default (such as divorce and relationship breakdown). Despite the large amount of research on MPPI, its overall impact on reducing arrears has yet to be systematically assessed in the context of a household model of mortgage risk that holds other factors constant. There is an apparent contradiction between micro and macro estimates of the "equity" effect (the tendency for borrowers to default when the value of their house falls below the value of their mortgage). Macro estimates suggest a huge equity effect whereas current UK micro studies find no equity effect at all. More research is needed to resolve this contradiction. 
Initial pooled logit results on the first 12 waves of the BHPS appear to confirm the curious contradiction between micro and macro studies: we found no evidence that housing equity (either initial or current) influenced the odds of falling into arrears. The probability of unemployment (which we found to be highly correlated with the probability of negative income change and the probability of ill health), in contrast, was highly significant. We also find evidence that MPPI does reduce the risk of arrears, but less so than having savings (though both variables are measured rather crudely). Regarding the impact of the major reforms of ISMI, we find no perceptible structural change after 1995.

\section{References:}

Boheim, R. and Taylor, M. (2000) My Home was my Castle: Evictions and Repossessions in Britain, Journal of Housing Economics, 9, pp. 287-319.

Buck, N., Gershuny, J., Rose, D. and Scott, J. (1994) Changing Households - The British Household Panel Survey. ESRC Research Center on Micro-Social Change, U.K.

Burrows, R. (1998) Mortgage Indebtedness in England: An 'Epidemiology'. Housing Studies. York, UK. Vol. 13, No. 1, pp. 5-22.

Case, K. and Shiller, R. (1996) Mortgage Default Risk and Real Estate Prices: The Use of IndexBased Futures and Options in Real Estate. Journal of Housing Research. 7(2), 243-257.

CML (2005) Repossession Risk Review January 2005, Council for Mortgage Lenders, London.

Ford, J., Quilgars, D., Burrows, R. and Rhodes, D. (2004) "Homeowners Risk and Safety Nets: Mortgage Payment Protection Insurance and Beyond”, ODPM, London.

Ford, J.; Kempson, E. and Wilson, M. (1995) Mortgage Arrears and Possessions: Perspectives from Borrowers, Lenders and the Courts. London, HMSO.

FSA (2005) Financial Risk Outlook 2005, Financial Services Authority, London.

Institute for Social and Economic Research. British Household Panel Survey (B.H.P.S.). Keeping Track: A Guide to Longitudinal Resources. www.iser.essex.ac.uk/ulsc/projects/ldr4ss/results/results.php.

Jackson, J. and Kaserman, D. (1980) Default Risk on Home Mortgage Loans: A Test of Competing Hypotheses. The Journal of Risk and Insurance. US. Vol. 4, pp. 678-690.

Kemp, P. and Pryce, G. (2002) Evaluating the Mortgage Safety Net. Council for Mortgage Lenders, London.

Kemp, Peter and Pryce, Gwilym. Evaluating the Mortgage Safety Net. Council of Mortgage Lenders Research. London, UK. 2001.

Kempson, E.; Ford, J. and Quilgars, D. Unsafe Safety-Nets. The Centre for Housing Policy, University of York. York, UK, 1999.

Lambrecht, B.; Perraudin, W. and Satchell, S. (1997) Time to Default in the UK Mortgage Market. Economic Modelling. Vol. 14, pp. 485-99.

Maclennan, D.; Meen, G.; Gibb, K.; and Stephens, M. (1997) Fixed Commitments, Uncertain Incomes: Sustainable Owner-Occupation and the Economy. Joseph Rowntree Foundation, York.

Muellbauer, J. and Cameron, G. (1997) A Regional Analysis of Mortgage Possessions: Causes, Trends and Future Prospects, Housing Finance, 34, pp. 25-34.

OEF (2001) The Relationship Between Mortgage Possessions and the Economic Cycle, Oxford Economic Forecasting, Report to the ABI.

Pryce, G. and Keoghan, M. Determinants of Mortgage Protection Insurance Take-up. Housing Studies. Vol. 16, No. 2, pp. 179-198, 2001.

Pryce, G. and Keoghan, M. (2002) Unemployment Insurance for Mortgage Borrowers: Is it Viable and Does it Cover those Most in Need? European Journal of Housing Policy. Vol. 2, No. 1 , pp. 87-114.

Pryce, G. (2002) Theory and Estimation of the Mortgage Payment Protection Insurance Decision. Scottish Journal of Political Economy. Vol. 49, No. 2, pp. 216-234, 2002. 